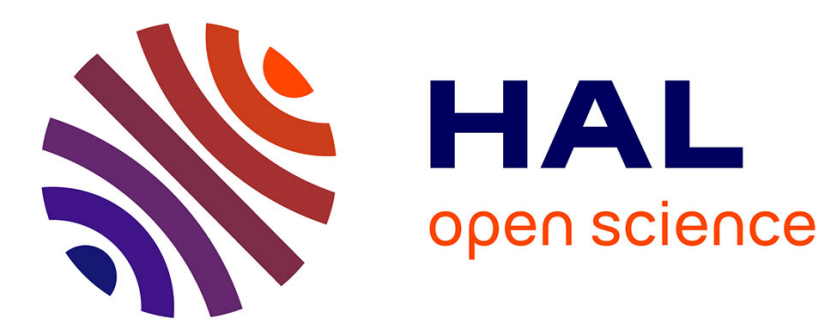

\title{
Le thème iconographique du lion dans les inscriptions médiévales
}

\author{
Robert Favreau
}

\section{To cite this version:}

Robert Favreau. Le thème iconographique du lion dans les inscriptions médiévales. Comptesrendus des séances de l'Académie des inscriptions et belles-lettres, 1991, 135 (3), pp.613-636. 10.3406/crai.1991.15027 . halshs-03203022

\section{HAL Id: halshs-03203022 https://shs.hal.science/halshs-03203022}

Submitted on 20 Apr 2021

HAL is a multi-disciplinary open access archive for the deposit and dissemination of scientific research documents, whether they are published or not. The documents may come from teaching and research institutions in France or abroad, or from public or private research centers.
L'archive ouverte pluridisciplinaire HAL, est destinée au dépôt et à la diffusion de documents scientifiques de niveau recherche, publiés ou non, émanant des établissements d'enseignement et de recherche français ou étrangers, des laboratoires publics ou privés. 


\section{Le thème iconographique du lion dans les inscriptions médiévales} Robert Favreau

Citer ce document / Cite this document :

Favreau Robert. Le thème iconographique du lion dans les inscriptions médiévales. In: Comptes rendus des séances de l'Académie des Inscriptions et Belles-Lettres, 135 année, N. 3, 1991. pp. 613-636;

doi : https://doi.org/10.3406/crai.1991.15027

https://www.persee.fr/doc/crai_0065-0536_1991_num_135_3_15027

Fichier pdf généré le 21/05/2018 


\section{COMMUNICATION}

\section{LE THĖME ICONOGRAPHIQUE DU LION}

DANS LES INSCRIPTIONS MÉDIÉVALES,

PAR M. ROBERT FAVREAU, CORRESPONDANT DE L'ACADEMIE

Le lion est très souvent représenté dans l'art, et ce dès la plus haute antiquité. Il peut avoir des valeurs très diverses, aussi bien négatives que positives. Aussi les inscriptions qui souvent l'accompagnent dans ses représentations médiévales sont précieuses pour confirmer ou éclairer l'iconographie et nous permettre d'être assurés de l'intention de l'auteur.

Trois personnages de l'Ancien Testament ont été confrontés au lion, Samson, David et Daniel. Samson s'apprêtait à prendre pour épouse une fille des Philistins, et comme il se rendait à Timna pour s'entretenir avec elle, * il vit un jeune lion qui venait à sa rencontre en rugissant. L'esprit de Yahvé fondit sur lui, sans rien avoir en main. Samson déchira le lion comme on déchire un chevreau " (Juges, XIV, 5-6). Nouvel Hercule vainqueur du lion de Némée, Samson est une figure du Christ triomphant de Satan, des forces du mal, de la mort. Un sermon originaire d'Afrique et attribué à Augustin le dit clairement : "Samson, c'est le Christ, admirable par sa beauté, très puissant par sa force ", la fille des Philistins c'est l'Église qui sera convoquée des nations païennes pour que le Christ l'épouse, le lion c'est " le monde, ceux qui aiment ce siècle, le fils du diable, le peuple des impies, qui... a osé résister au Seigneur "1. Rupert de Deutz ne dira pas autre chose, lorsque, commentant ce passage, il écrira que le lion cruel - saevus - qui se présente à l'encontre de Samson est "la figure du diable "2. On conserve au château de Montesquiou (Gers) un bas-relief de la fin $\mathrm{du} \mathrm{XI}^{\mathrm{e}}$ siècle, qui provient du tympan de Saint-Orens d'Auch et illustre l'épisode de la lutte de Samson contre le lion de Timna. L'inscription souligne le courage de Samson et la cruauté du lion :

1. Patrologie latine, 46, col. 821, sermo I, De cereo paschali. La Patrologie sera abrégée désormais $P L$.

2. De sancta Trinitate et operibus ejus. Libri $X-X X V I$, éd. Raban Haacke, Turnhout, 1972 , p. 1172 (Corpus christianorum. Continuatio medievalis, XX);PL, 167, col. 1043. 


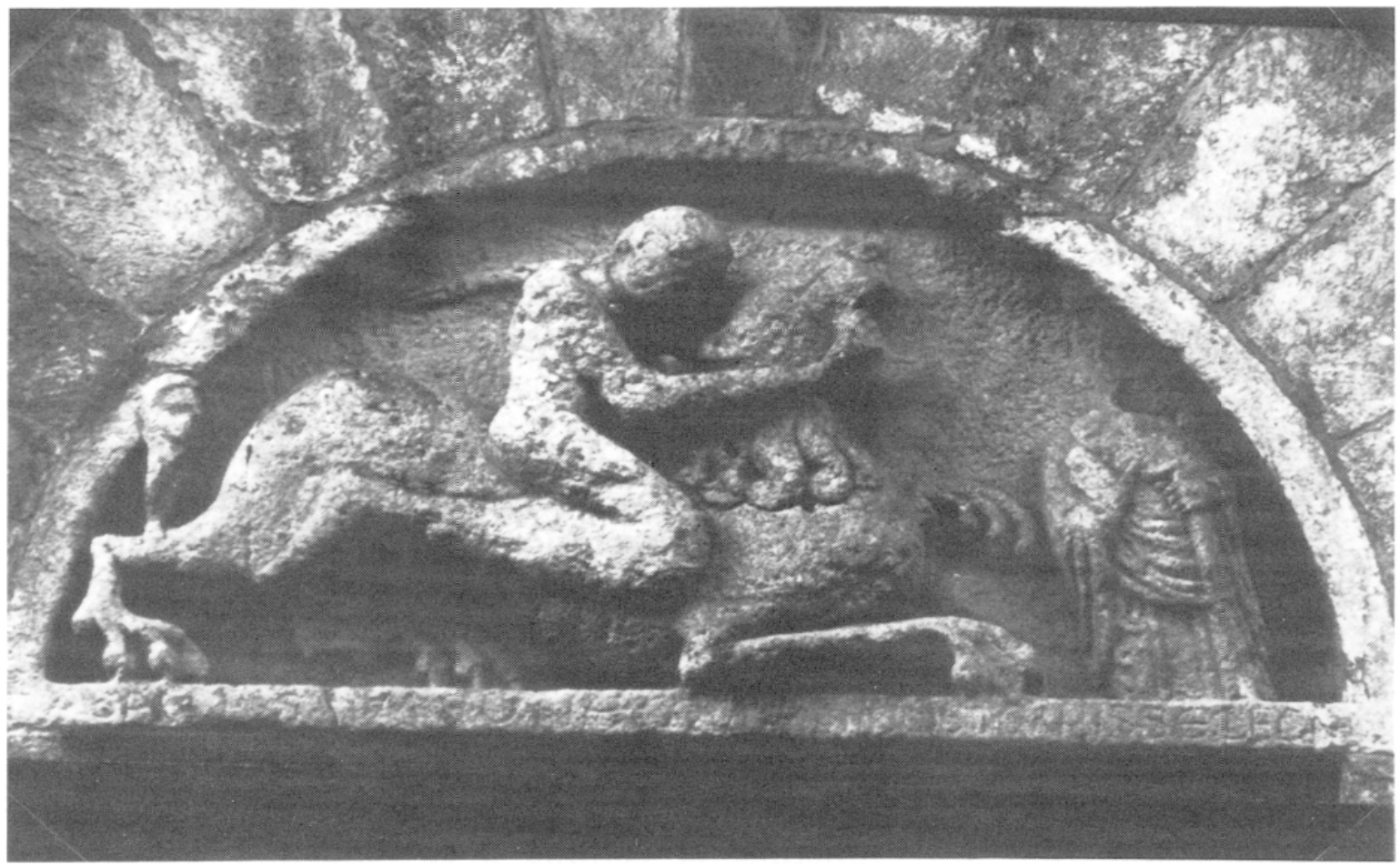

Fig. 1. - Mauriac (Cantal),

tympan de l'ancienne porte du doyenné : Samson et le lion (cl. J. Michaud, CESCM/CNRS).

VIRTUS SAMSONIS SEVI DOMAT ORA LEONIS

"Le courage de Samson maîtrise la gueule du lion en fureur ${ }^{3}$.

Le mot ora est peut-être appelé par la composition de l'hexamètre ; peut-être aussi fait-il référence au fait que Samson, quelques jours plus tard, trouvera un essaim d'abeilles et du miel dans la bouche du cadavre - in ore leonis.

A la porte de l'ancien doyenné de Mauriac, un tympan du début $\mathrm{du} \mathrm{XII}^{\mathrm{e}}$ siècle représente également Samson qui terrasse le lion; l'inscription attire l'attention du spectateur sur le triomphe du héros qui, selon l'Écriture, domine à mains nues le redoutable fauve :

ASPICE SANSONEM MANIBUS SUPERESSE LEONEM ${ }^{4}$ (fig. 1).

La force de Samson est aussi exprimée dans le fait qu'il déchire le lion en morceaux de ses mains nues, ce qui est retenu dans le

3. Corpus des inscriptions de la France médiévale. 6. Gers, Landes, Lot-et-Garonne, PyrénéesAtlantiques, par Robert Favreau, Bernadette Leplant, Jean Michaud, Paris, 1981, p. 56-57. Le Corpus sera désormais abrégé en CIFM.

4. A. Mayeux, "Tympan sculpté de la porte du doyenné de Mauriac ", Bull. Soc. nat. des antiquaires de France, 1927, p. 232-236. 
texte gravé au montant droit du portail roman de San Marcello de Capoue :

DIVISIT SANSON TORUM PER FRUSTA LEONEM 5 .

Dans ces trois exemples Samson n'est pas expressément donné comme la figure du Christ, mais tous les commentaires patristiques invitent à cette lecture. La déchirure du cadavre en morceaux, c'est aussi le Christ qui « a dispersé le peuple des Juifs et l'a envoyé dans les différentes parties " du monde, selon l'interprétation du Liber de promissionibus et praedictionibus Dei, de Quodvultdeus ${ }^{6}$. Dans deux autres inscriptions le qualificatif de fortis renvoie plus étroitement au Christ, comme le montre le parallèle fait par Augustin entre le fortissimus Samson et le Christ fortitudine potentissimus. De l'église abbatiale Saint-Sauveur à Nevers vient un chapiteau de Samson au lion avec l'inscription: SAMSON ADEST FORTIS", "voici le fort Samson ", et à Hanovre, vers 1200, une autre inscription dit :

SANSON HUNC FORTEM FORTIS VICERATQUE LEONEM ${ }^{8}$.

Le retable de Klosterneubourg, dont on sait combien il traduit une pensée fortement élaborée, met en scène Samson et le lion, SAMSON CUM LEONE, en parallèle avec les plaies d'Égypte (temps " avant la Loi ») et la destruction de l'enfer (temps " sous la grâce "), et l'inscription dit clairement que Samson est la figure du Christ, le lion la figure de la mort :

+ VIR GERIT ISTE TUAM, LEO MORTIS, CHRISTE, FIGURAM 9 (fig. 2). "Cet homme porte ta figure, ô Christ, le lion porte la figure de la mort."

L'inscription peut être seulement d'identification, comme le SANSON et LEO d'un bassin du XII ${ }^{\mathfrak{e}}$ siècle à Piobesi Torinese ${ }^{10}$.

Autre grand personnage vétéro-testamentaire, David, lorsqu'il s'offre à Saül pour affronter le Philistin Goliath, lui dit que "lorsqu'il faisait

5. Heinrich Wilhelm Schulz, Denkmaeler der Kunst des Mittelalters in Unteritalien, Dresde, II, 1860, p. 165 ; Mario D'Onofrio et Valentino Pace, Campanie romaine, La Pierre-quiVire, 1981, p. 42.

6. Opera Quodvultdeo Carthaginiensi episcopo tributa, éd. R. Braun, Turnhout, 1976, p. 109 (Corpus christianorum. Series latina LX) : "decerpsit populum fudaeorum ut catulum leonis, misitque per partes... per orbem ", $P L, 51$, col. 791 .

7. N. J. Morellet, J.-C. Barat, E. Bussière, Le Nivernais, album historique et pittoresque, rééd., Grenoble, I, 1969, p. 119 ; Marcel Anfray, L'architecture religieuse du Nivernais au Moyen Âge. Les églises romanes, Paris, 1951, p. 144, 267, pl. 50.

8. Peter Bloch, "Löwe \#, dans Lexicon der christlichen Ikonographie... I. Allgemeine Ikonographie, LABAN-RUTH, Rome, Fribourg, Bâle et Vienne, 1971, col. 116.

9. Helmut Buschhausen, Der Verduner Altar. Das Emailwerk des Nikolaus von Verdun im Stift Klosterneuburg, Vienne, 1980, p. 64 et fig. 36.

10. Arthur Kingsley Porter, Lombard Architecture, III, New Haven/Londres/Oxford, 1917, p. 285. 


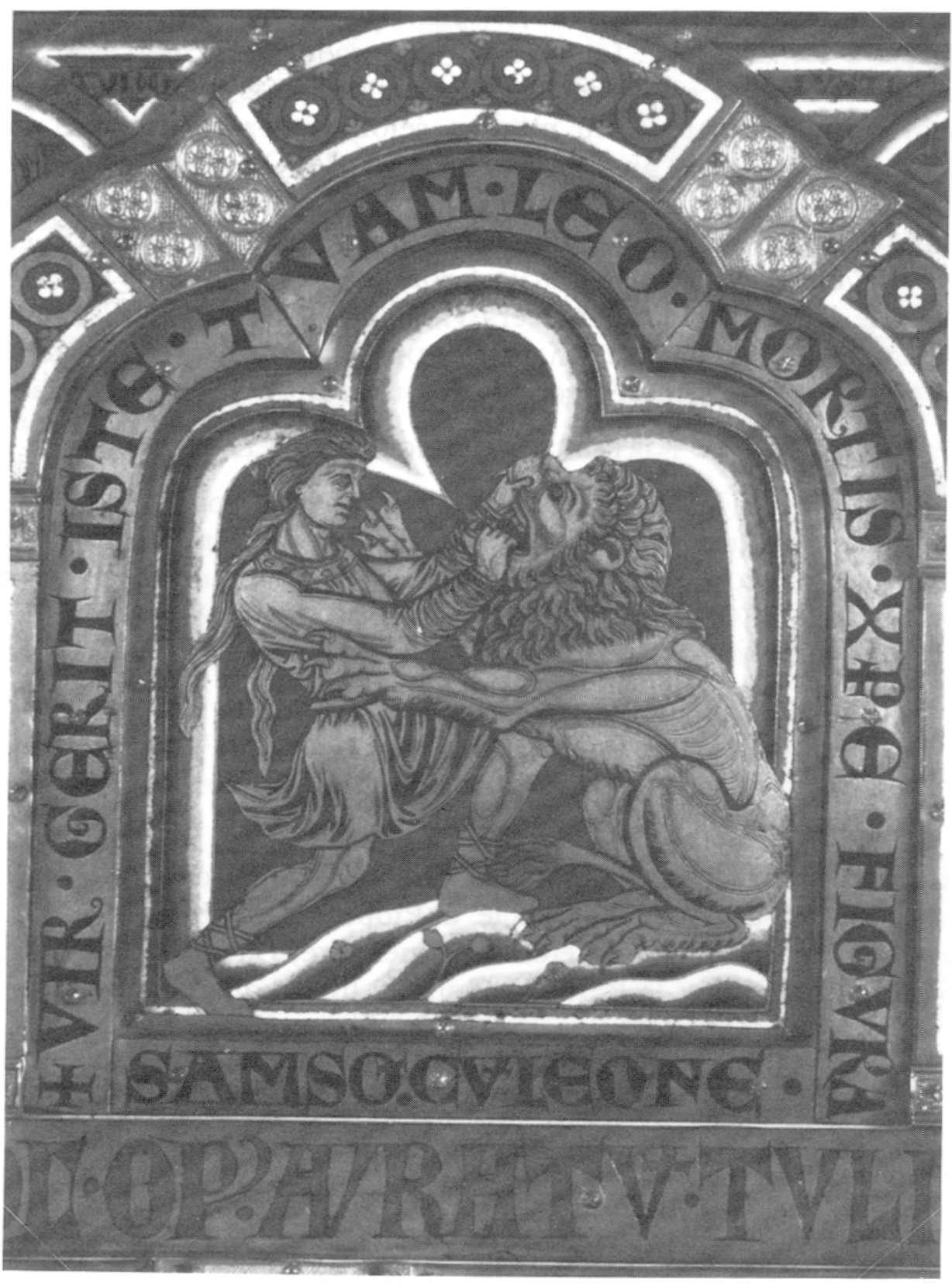

FIG. 2. - Klosterneubourg (Autriche), retable: Samson et le lion (H. Buschhausen, Der Verduner Altar.

Das Emailwerk des Nikolaus von Verdun im Stift Klosterneuburg, Vienne, 1980, pl. 36). 
paître les brebis de son père et que venait un lion ou un ours qui enlevait une brebis du troupeau, il le poursuivait, le frappait et arrachait la brebis de sa gueule... Yahvé qui m'a sauvé de la griffe du lion et de l'ours me sauvera des mains de ce Philistin " (1 Samuel, XVII, 34-37). La crosse de Chartres conservée au Musée du Bargello à Florence a repris cette scène mais avec l'ours'11. David qui terrasse le lion est accompagné sur la lanterne de Bégon, au trésor de Conques, de l'inscription :

SIC NOSTER DAVID S[UBOLEM SA]TANAM SUPERAVIT

"Ainsi notre David triompha de la lignée satanique »12.

"Leo et ursus a David occisi, diabolus a Christo spoliatus ", déclare saint Césaire dans un de ses sermons ${ }^{13}$.

Daniel dans la fosse aux lions est le thème le plus répandu. Il était un des proches collaborateurs du roi Darius. Les autres chefs et satrapes du royaume le dénoncèrent au roi parce que Daniel priait trois fois par jour son Dieu, contrairement à la loi des Mèdes et des Perses. Alors le roi fit jeter Daniel dans la fosse aux lions. Celui-ci y resta toute la nuit, mais Dieu envoya son ange qui ferma la gueule des lions (Daniel, VI, 2-29). Les chrétiens virent tôt dans ce récit un symbole de la Résurrection : ce thème se trouve dès la fin du ier siècle dans la catacombe de Domitille et trente-neuf fois dans l'ensemble des peintures des catacombes. C'était aussi une éclatante manifestation de la protection de Dieu envers ses serviteurs fidèles, en sorte que l'êpisode figurera dans les premières liturgies des défunts. Dans l'Ordo commendationis animae, qui en fit très tôt partie, on implore la clémence du Seigneur pour le défunt : "Libera, Domine, animam ejus, sicut liberasti Danielem de lacu leonum ". Si le premier manuscrit de cet Ordo est du viII siècle $^{14}$, la patène de verre trouvée à Podgorica (Titograd, Yougoslavie) en est un témoin plus ancien, avec l'inscription : DANIEL DE LACO LEONIS, parmi les autres invocations de $1^{\prime}$ Ordo commendationis ${ }^{15}$. Une épitaphe du cloître de San Lorenzo in Agro Verano à Rome en 1068 reprendra cette même invocation : "OREMUS DEUS QUI DANIELEM A FERIS MORSIBUS... LIBERASTI, LIBERA, DOMINE, FAMULUM TUUM... $» 16$.

11. English Romanesque Art 1066-1200, Londres, 1984, n 282, p. 266.

12. CIFM 9. Aveyron, Lot, Tarn, par R. Favreau, J. Michaud, B. Leplant, Paris, 1984, p. 47-48.

13. $P L, 39$, col. 1819 (dans les œuvres d'Augustin).

14. L. Gougaud, "Analecta historico-ascetica. Étude sur les Ordines commendationis animae ", dans Ephemerides liturgicae, XLIX, 1935, p. 1-27 ; Joseph Ntedika, L'évocation de l'au-delà dans la prière pour les morts. Étude de patristique et de liturgie latines (IV'-VII' s.), Louvain et Paris, 1971, p. 72-73 (Recherches africaines de théologie. Travaux de la Faculté de Théologie de l'Université Lovanium de Kinshasa, 2).

15. Ernest Diehl, Inscriptiones latinae christianae veteres, I, Berlin, 1925, p. 471, no 2426 .

16. Vincenzo Forcella, Iscrizioni delle chiese e di altri edificii di Roma dal sec. XI ai giorni nostri, Rome, XII, 1878, $\mathrm{n}^{\circ}$ 564, p. 509 ; Angelo Silvagni, Monumenta epigraphica christiana saeculo XIII antiquiora, I. Roma, Rome, 1943, pl. XXI-2. 
Le sens de cette représentation de Daniel dans la fosse aux lions était si évident que les inscriptions qui l'accompagnent sont des plus simples et se bornent généralement à reprendre l'expression de lacus leonum qui est répétée onze fois dans le livre de Daniel. Ainsi en Afrique du Nord à l'époque chrétienne, DANIEL IN LACU LEONUM ou seulement DANIEl entre des lions ${ }^{17}$, à San Pedro de la Nave en Espagne à l'époque wisigothique tardive, UBI DANIEL MISSUS EST IN LAQUM LEONUM $^{18}$, et à l'époque romane, à Saint-Porchaire de Poitiers ${ }^{19}$, à Marestay près de Matha $^{20}$, à Marcilhac-sur-Céléel au cloître de Moissac 22, sur un chapiteau de la Daurade au Musée de Toulouse23, sur un chapiteau de la nef de Vézelay ${ }^{24}$ ou aux cathédrales de Bovino, de Fidenza, de Worms ${ }^{25}$.

C'est encore de la Bible, à savoir les psaumes, qu'il faut partir pour quelques autres représentations du lion comme un animal dangereux ou même maléfique. Le verset 22 du psaume XXII (XXI), Salva me ex ore leonis et a cornibus unicornium humilitatem meam, dont on a un rappel dans la seconde lettre à Timothée (IV, 17), Et liberatus sum de ore leonis, a son écho presque littéral dans une inscription de la façade ouest de la cathédrale de Pise :

DE ORE LEONIS LIBERA ME, DOMINE, ET A CORNIBUS UNICORNIUM HUMILITATEM MEAM ${ }^{26}$ (fig. 3).

17. E. Diehl, op. cit., I, p. $471, \mathrm{n}^{\circ} 2427$.

18. Emile Huebner, Inscriptionum Hispaniae christianarum supplementum, Berlin, 1900, p. $406, n^{\circ} 466$, chapiteau de la nef ; José Vives, Inscripciones cristanas de la España romana $y$ visigoda, Barcelone, $2^{\mathrm{e}}$ ed., 1969, p. 119, $\mathrm{n}^{\circ} 347$; Jacques Fontaine, L'art préroman hispanique, I, La Pierre-qui-Vire, 1973, p. 203, pl. 71.

19. CIFM, 1, Ville de Poitiers, par R. Favreau et J. Michaud, Paris et Poitiers, 1974, p. 92, $n^{\circ} 77$ : LEONES, chapiteau de la tour porche.

20. CIFM, 3. Charente-Charente-Maritime, Deux-Sèvres, par R. Favreau et J. Michaud, Poitiers, 1977, p. 95 : DANIEL IN LACU LEONUM, chapiteau.

21. CIFM, 9. Aveyron, Lot, Tarn, par R. Favreau, J. Michaud, B. Leplant, Paris, 1984, p. 103 : LEO, chapiteau du narthex.

22. CIFM, 8. Ariège, Haute-Garonne, Hautes Pyrénées, Haute-Garonne, par R. Favreau, J. Michaud, B. Leplant, Paris, 1982, p. 175 : LEO (deux fois), DANIELE MITTATUR ou MISE. RUNT IN LACUM LEONUM, chapiteau de la galerie occidentale.

23. CIFM, 7. Ville de Toulouse, par R. Favreau, J. Michaud, B. Leplant, Paris, 1982, n 33, p. 66-67 : DANIEL INTER LEONES.

24. Vézelay : DANIEL IN LACU LEONUM.

25. A Bovino : Daniel in Ca[vea] Cum leon[IBus] (Alfredo Petrucci, Cattedrali di Puglia, Rome, $2^{e}$ éd., 1964, p. 24 ; à Fidenza : DANIEL jUSTUS IN LACU LEONUM (Arthur Kingsley Porter, Lombard Architecture, II, 1916, p. 189); à Worms, ancien tympan, mur intérieur sud : Daniel in lacu leonum (Der Dom zu Worms. Wegweiser und Deutung, s.d., p. 14). On peut joindre à ces inscriptions deux vers du diacre Micon pour l'église de Saint-Riquier au IX ${ }^{e}$ siècle (Poetae latini aevi carolini, t. III, ed. L. Traube, Berlin, 1896, p. 359, MGH, Poetarum latinorum Medii Aevi, III).

26. L'article de W. Deonna, "Salva me de ore leonis. A propos de quelques chapiteaux romans de la cathédrale Saint-Pierre à Genève *, dans la Revue belge de philologie et d'histoire, t. 28, 1950, p. 479-511 est seulement consacré à quelques aspects de l'iconographie du lion ; Piero Sanpaolesi, Il duomo di Pisa e l'architettura romanica toscana delle origini, Pise, 1975, pl. LXXXII b. 


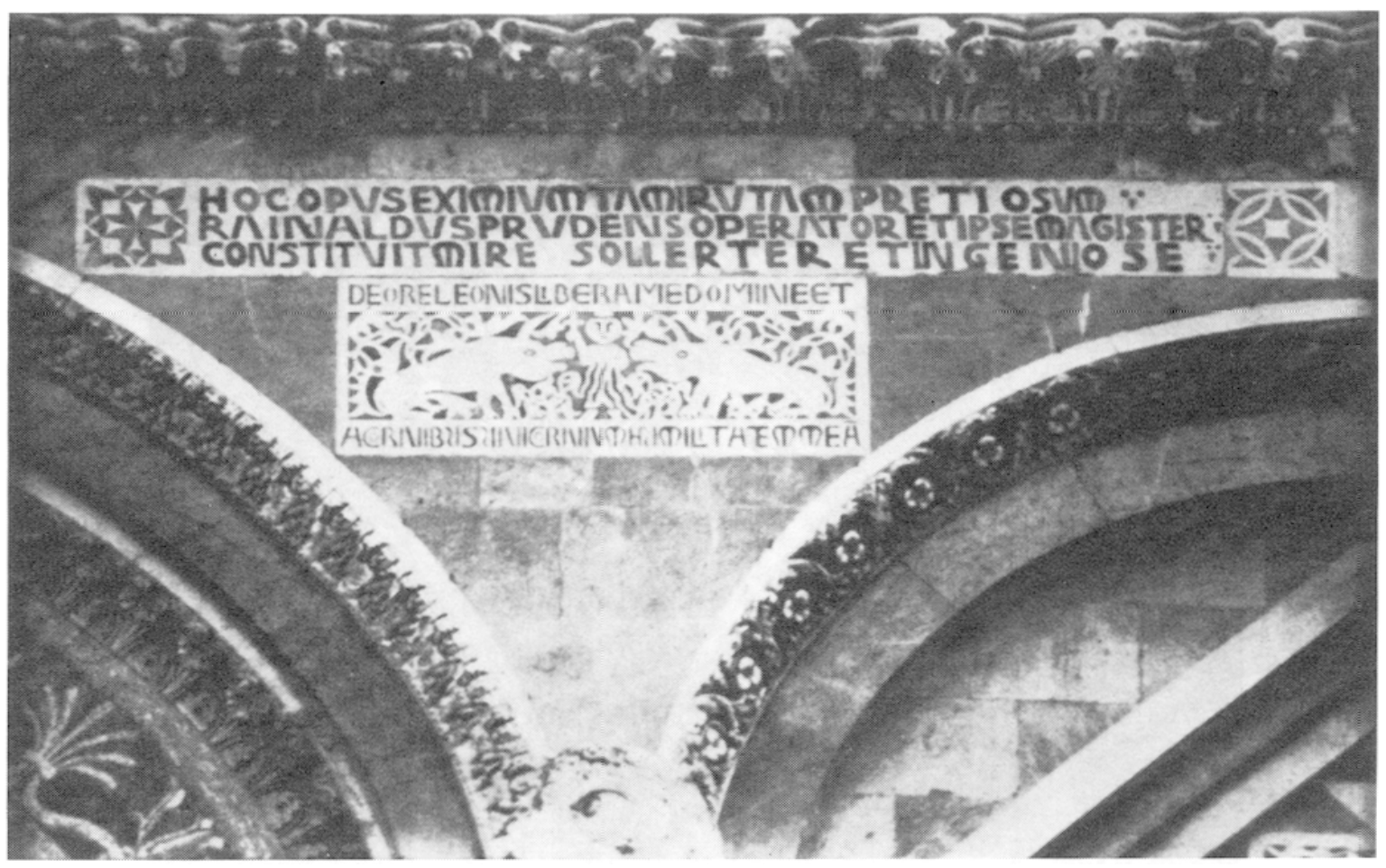

FIG. 3. - Pise (Italie), cathêdrale, façade ouest : "De ore leonis..."

(P. Sanpaolesi, Il duomo di Pisa e l'architettura romanica toscana delle origini, Pise, 1975, pl. LXXXII b).

"Libère-moi, Seigneur, de la gueule du lion, et des cornes du taureau ma pauvre âme."

L'inscription reprend en fait, textuellement un répons du dimanche de la Passion'27, ce qui lui fait rejoindre le sens de la figure de Daniel dans la fosse aux lions, résurrection et appel à la miséricorde divine.

Le verset $13 \mathrm{du}$ psaume XCI (XC), Super aspidem et basiliscum ambulabis, et conculcabis leonem et draconem, a connu une meilleure fortune dans l'épigraphie. Sur le diptyque d'ivoire de Genoelselderen, aux Musées royaux d'art et d'histoire de Bruxelles, de la fin du viII siècle, le Christ foule aux pieds les quatre animaux, et une inscription, en haut et sur les côtés, rappelle le psaume : UBI DOMINUS AMBULABIT SUPER ASPIDEM ET BASILISCUM ET CONCULCABIT LEONEM ET DRACONEM, tandis que sur le nimbe crucifere le mot REX affirme la supériorité du Rédempteur, qui porte la croix sur son 


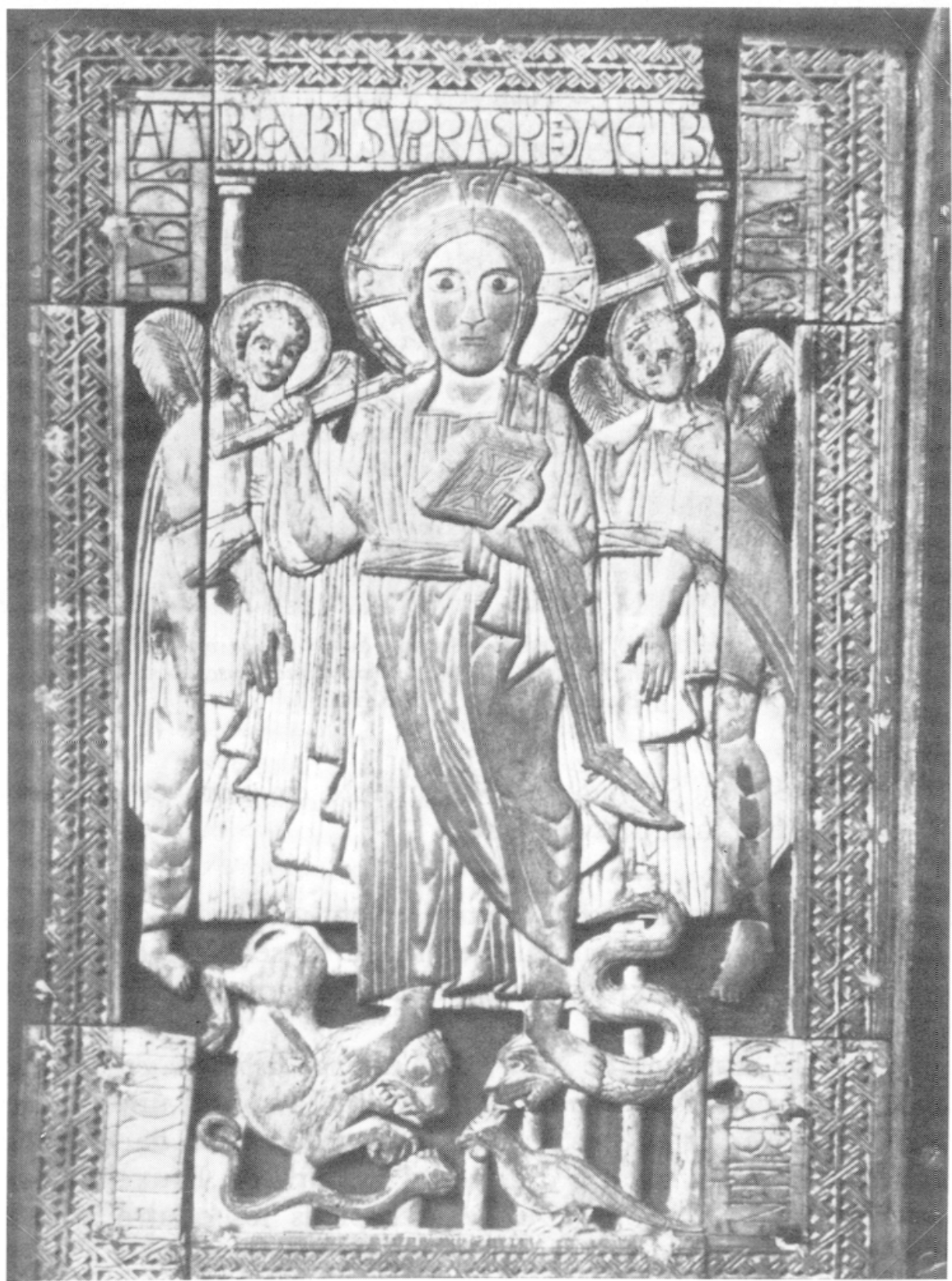

Fig. 4. - Bruxelles (Belgique),

Musées royaux d'art et d'histoire, diptyque d'ivoire de Genoelselderen (Charlemagne, Aix-la-Chapelle, 1965, pl. 104). 
épaule $^{28}$ (fig. 4). A la porte royale de la cathédrale de Modène le verset du psaume est exactement cité29, comme il l'est à peu près sur un bas-relief de l'église Notre-Dame de Maestricht, où le Christ est bien le Christ triomphant de l'Apocalypse portant l'alpha et l'omega (Apoc., I, 8) sur une tablette ${ }^{30}$. Au tympan de l'ancienne porte de réfectoire de Saint-Rambert-l'Ile-Barbe à Lyon, l'inscription versifiée renvoie à ce même verset du psaume, et souligne que les animaux cités doivent être considérés sur un plan mystique et non littéral :
ALFA ET O, PRIMUS FINIS, MIHI CONVENIT ERGO
ASPIS CALCATUR, BASILISCUS SED SUPERATUR,
SICQUE LEO PARITERQUE DRACO SUNT MISTICA VERO.

L'inscription ajoutée à la seconde archivolte peut être tenue pour le commentaire du psaume : "La mer, la terre, le ciel, je les ai soumis, moi qui suis le seul roi, moi qui, sur la croix, par ma force ai vaincu les méfaits de la mort »31. Ce verset du psaume XCI sert de trait à l'office du premier dimanche de Carême, le temps liturgique qui ouvre sur la Passion et la Résurrection. Il y a là une interprétation quelque peu différente de l'interprétation traditionnelle des commentateurs qui, d'Augustin à Pierre Lombard, voient naturellement le Christ dans celui qui foule aux pieds les animaux maléfiques, mais identifient le lion à la bête cruelle (saeviens) qui fit périr les martyrs innocents ou chez les auteurs plus récents, au diable ${ }^{32}$.

Le lion a aussi une valeur positive. Les inscriptions qui en têmoignent renvoient à la Bible - le lion est "le plus fort de tous les animaux " dit le livre des Proverbes (XXX, 30) -, mais aussi, et bien davantage, aux bestiaires. Au départ il y a le Physiologus grec, compilé sans doute à Alexandrie au $\mathrm{II}^{\mathrm{e}}$ ou $\mathrm{II}^{\mathrm{e}}$ siècle, et traduit en latin dès le IV siècle. La plus importante translation, le Physiologus latinus, des $\mathrm{VIII}^{\mathrm{e}}-\mathrm{IX}^{\mathrm{e}}$ siècles, sera à la base de tous les bestiaires médiévaux ${ }^{33}$. Dans le Physiologus et dans tous les bestiaires, le lion

28. L'empire carolingien, par J. Hubert, J. Porcher, W. F. Volbach, Paris, 1968, p. 220, fig. 200 (L'univers des formes); Charlemagne, Aix-la-Chapelle, 1965, p. 345-346, $\mathrm{n}^{\circ} 534$; Dictionnaire d'archéologie chrétienne et de liturgie, VI-1, Paris, 1924, col. 1001-1004.

29. Augusto Campana, "La testimonianza delle iscrizioni ", dans Lanfranco e Wiligelmo. Il duomo di Modena, p. 400.

30. Lisbeth Tollenaere, La sculpture sur pierre dans l'ancien diocèse de Liège à l'époque romane, Grenoble, 1957, p. 274, pl. 20 A.

31. Abbé Roux, "Précis historique sur l'Ile-Barbe ", dans Bulletin monumental, X, 1844, p. 77 ; Victor Terret, La sculpture bourguignonne aux XII et XIII' siècles. Ses origines et ses sources d'inspiration. Cluny, Autun et Paris, 1914, p. 27.

32. $P L, 26$, col. 1100 (n'est pas de Jérôme ; peut-être de Jean Diacre); 37, col. 1168 (Augustin); 70, col. 654 (Cassiodore); 113, col. 1000 (Glossa ordinaria, i.e. Anselme de Laon plutôt que Walafrid Strabon); 164, col. 1055 (Bruno d'Asti), 183, col. 242 (s. Bernard); 191, col. 853 (Pierre Lombard), etc.

33. Francis B. Carmody, Physiologus latinus. Éditions préliminaires versio B, Paris, 1939 ; Florence McCulloch, Mediaeval Latin and French Bestiaries, The University of North Carolina 
est cité en premier, car il est le roi des animaux. "Leo autem graece, latine $\langle\langle$ rex $\rangle\rangle$ interpretatur, eo quod princeps sit omnium bestiarum ", écrit Isidore de Séville dans ses Étymologies ${ }^{34}$, ce que reprend textuellement Raban Maur au IX ${ }^{\mathrm{e}}$ siècle ${ }^{35}$, et que réaffirme le $D e$ bestiis attribué à Hugues de Saint-Victor au XII ${ }^{\mathrm{e}}$ siècle, est rex ferarum et omnium quadrupedum princeps ${ }^{36}$. L'assimilation du Christ au lion est dès lors aisée. Raban Maur l'affirme clairement : le lion, roi des animaux, est par sa force le type du Christ, roi des rois et seigneur des seigneurs ${ }^{37}$.

Dans le Physiologus le lion est décrit avec trois traits caractéristiques. D'abord il dort les yeux ouverts et ne relâche jamais sa vigilance. Ce premier trait se trouve dans le De animalium natura de Claudius Aelianus ${ }^{38}$. En deuxième lieu il épargne ceux qui sont abattus : " Le lion est le seul fauve qui montre de la clémence envers les suppliants, il épargne ceux qu'il a terrassés ", affirmait déjà Pline l'Ancien dans son Histoire naturelle ${ }^{39}$, repris par Caius Julius Solin dans son Polyhistor 40 . Le troisième trait est le plus surprenant : les lionceaux, à leur naissance, demeurent sans vie pendant trois jours et trois nuits, puis leur père arrive, et par son souffle ou son rugissement, il leur redonne vie. Tous les auteurs, à la suite du Physiologus, en ont fait l'application au Christ, en se référant à un verset des bénédictions de Jacob (Genèse, LXIX, 9) : "Catulus leonis fuda. Ad praedam, fili mei, ascendisti. Requiescens accubuisti ut leo, et quasi laena, quis suscitabit eum ", "Juda est un jeune lion; de la proie, mon fils, tu es remonté ; il s'est accroupi, s'est couché comme un lion, comme une lionne : qui le ferait lever ?", et en y voyant une figure de la Résurrection. Ainsi dès la fin du Ive siècle Rufin d'Aquilée souligne que le catulus leonis désigne le Christ non seulement physiquement mais bien plutôt de façon tropologique et il cite expressément le Physio$\log u s^{41}$. Il est fort probable, et c'est ce qui ressort du texte de Rufin, que c'est à travers le Physiologus que le verset plutôt obscur de la bénédiction de Jacob a été appliqué à la Résurrection.

Press, 1960 (University of North Carolina. Studies in the Romance Languages and Literatures, number 33).

34. $P L, 82$, col. 434 .

35. PL, 111, col. 217.

36. $P L, 177$, col. 56 ; serait d'Alain de Lille?

37. $P L, 111$, col. 217 : "Leo, qui rex est bestiarum, per fortitudinem typum tenet Christi, qui est rex regum et dominus dominantium ".

38. Livre V, chap. XXXIX, éd. Genève, 1616, p. 294.

39. Livre VIII, chap. XIX, éd. et trad. A. Ernout, Paris, 1952, p. 40 (Collection des Universités de France publiée sous le patronage de l'Association Guillaume Budé).

40. Chapitre Xxvill, éd. et trad. A. Agnant, Paris, 1847, p. 210-211.

41. Tyranii Rufini, Opera, éd. Manlius Simonetti, De benedictionibus patriarchum. Liber primus. Benedictio fudae, Turnhout, 1961, p. 193 (Corpus christianorum. Series latina XX); $P L, 21$, col. 302 . 
Chacun de ces traits du Physiologus a été repris dans l'iconographie et l'épigraphie. Le lion dort les yeux ouverts, il est toujours en état de veille. Ce trait a été commenté de deux manières. Le Christ, comme le lion, ne relâche jamais sa vigilance à l'égard de son troupeau. L'auteur du Physiologus, attribué à tort à Hildebert de Lavardin, le dit clairement ${ }^{42}$, comme Geoffroy d'Admont dans son Liber de benedictionibus facob patriarchae ${ }^{43}$, ou l'auteur du De bestiis, attribué à tort à Hugues de Saint-Victor ${ }^{44}$. Le Christ est donc celui qui veille sur son peuple. C'est peut-être ce que veut signifier Raban Maur lorsqu'il écrit : "Leones praepositi Ecclesiae intelliguntur. Unde in templo Domini leones, cum bubus, ex aere, in basibus templi fieri praecipiuntur " ${ }^{45}$. C'est en tout cas la raison - ou du moins une des raisons - pour laquelle des lions sont souvent représentés veillant à la porte des sanctuaires. Une inscription le dit expressément à la porte du lion de la cathédrale de Verdun, consacrée au milieu du XII ${ }^{e}$ siècle.

\section{EST LEO SED CUSTOS OCULIS QUIA DORMIT APERTIS TEMPLORUM IDCIRCO PONITUR ANTE FORAS 46.}

Ce texte sera repris textuellement par Alciati au $\mathrm{XVI}^{e}$ siècle ${ }^{47}$. C'est peut-être le sens des deux lions qui, à Santa Cruz de la Serós, au XIr siècle, encadrent le chrisme, symbole de celui qui est « la porte perpétuelle " ouverte à tous les fidèles ${ }^{48}$. La seconde manière d'interpréter ce trait du lion, qui dort les yeux ouverts, c'est d'y voir un symbole de la mort et résurrection du Christ. Grégoire le Grand le dit dêjà dans une homélie sur Ézéchiel49, et, après lui, Raoul Ardent, dans un de ses sermons50, et l'auteur du $D e$

42. $P L, 171$, col. 1217 : «Tu nos custodis, tu nullo tempore dormis.

43. $P L, 174$, col. 1140 .

Ne demat quemquem proprio lupus e grege raptum."

44. PL, 177, col. 57 : "Secunda natura leonis est quod cum dormit oculos apertos habere videtur. Quod bene dicitur de Christo in Canticis canticorum : Ego dormio et cor meum vigilat. " 45. $P L, 111$, col. 218.

46. Franz Ronig, "Die Buchmalerei des 11. und 12. Jahrhunderts in Verdun *, Aachener Kunstblätter, 38, 1969, p. 14 ; Esther Gosebruch, "Das Löwenportal ", Königslutter und Oberitalien. Kunst des 12. Fahrhunderts in Sachsen, $2^{e}$ éd., Braunschweig, 1982, p. 75, n. 2 (Sonderausstellung im Braunschweigischen Landesmuseum vom 12. Oktober bis 23 November 1980).

47. H. Leclercq, * Lion ", dans Dictionnaire d'archéologie chrétienne et de liturgie, XI-1, Paris, 1930, col. 1199.

48. Antonio Duran Gudiol, "Las inscripciones medievales de la provincia de Huesca ", dans Estudios de edad media de la corona de Aragon, VIII, 1967, p. 61-62, $n^{\circ} 78$.

49. Grégoire le Grand, Homiliae in Hiezechihelem prophetam, êd. Marc Adriaen, Turnhout, 1971 , p. $47:$ : Leo etiam apertis oculis dormire perhibetur, quia in ipsa morte in qua ex humanitate Redemptor noster dormire potuit, ex divinitate sua immortalis permanendo vigilavit" (Corpus christianorum Series latina CXLII); $P L, 76$, col. 815 .

50. PL, 155, col. 1515 . 
bestiis ${ }^{51}$. Une inscription reprend ce sens avec une signification particulière, car elle se trouvait sur une paroi de la tombe sacrée dans la basilique du Saint-Sépulcre à Jérusalem :

\section{MORTUUS HIC JACUIT MORTEM DUM MORTE PREMIT \\ HIC LEO DORMIVIT, QUI PERVIGIL OMNIA TRIVIT 52.}

La deuxième caractéristique du lion, selon le Physiologus et les bestiaires, c'est qu'il épargne ceux qui sont prosternés à terre : prostratis parcit écrit Pline l'Ancien, prostratis parcunt reprend Solin. La description d'Isidore de Séville dans ses Étymologies : "Circa hominem leonum natura est benigna, ut nisi laesi nequeant irasci. Patet enim misericordia exemplis assiduis. Prostratis enim parcunt "53, est redonnée, à un mot près, par Raban Maur ${ }^{54}$, et le même trait est rapporté par l'auteur du De bestiis au XII siècle55. En dehors des bestiaires Rupert de Deutz commente un passage du prophète Osée $(\mathrm{V}, 14)$ à partir de ce même caractère : "Les naturalistes (physici) rapportent que le lion épargne l'homme prostré. La colère du Seigneur sera terrible, mais elle épargnera ceux qui sont prostrés et qui reconnaissent leurs péchés "56. "Le lion, roi des bêtes sauvages, épargne ceux qui lui sont soumis ", disent aussi les Carmina burana, qui invitent les princes de la terre à faire de même ${ }^{57}$, et le second Primat fera écho à cette description du lion au début du XIII siècle $^{58}$.

Une inscription à l'entrée de la seconde porte du Capitole à Rome accompagnait la représentation d'un lion à l'aspect féroce, qui se dressait devant un lionceau couché à ses pieds ; on montrait la scène et l'inscription qui la commentait à chaque sénateur lorsqu'il entrait au Capitole pour y exercer son office :

IRATUS RECOLE QUOD NOBILIS IRA LEONIS

IN SIBI PROSTRATIS SE NEGAT ESSE FERAM ${ }^{59}$.

51. PL, 177, col. 57 : "Dormivit enim caro in cruce moriendo, divinitas vero vigilabat cuncta protegendo, unde psalmus: Ecce non dormitabit neque dormiet, qui custodit Israel (Ps. CXXI (CXX), 4) ".

52. Sabino de Sandoli, Corpus inscriptionum crucesignatorum Terrae Sanctae, Jérusalem, 1974, p. $9, \mathrm{n}^{\circ} 7$.

53. $P L, 82$, col. 434.

54. $P L, 111$, col. 217 .

55. $P L, 177$, col. 57.

56. $P L, 168$, col. 193-194.

57. Carmina burana. I Bd : Text. 3. Die Trink- und Spielerdieder. Die geistlichen Dramen, éd. Otto Schumann et Bernhard Bischoff, Heidelberg, 1970, $\mathrm{n}^{\circ} 191$, p. 8.

58. B. Haureau, * Notice sur un manuscrit de la reine Christine à la Bibliothèque du Vatican *, dans Notices et extraits des manuscrits de la Bibliothèque nationale et autres bibliothèques, XXIX, 1880, p. 269 : Parcit enim subditis leo, rex ferarum.

59. Inscriptiones urbis Romae latinae, éd. G. Henzen, J.-B. De Rossi, E. Bormann, Chr. Huelsen, t. VI, pars quinta..., Berlin, 1885, p. $4^{\star}, \mathrm{n}^{\circ} 3^{\star a}$ (Corpus inscriptionum latinarum, VI-5). On trouve aussi ce distique dans un manuscrit de Munich (Clm 23108, fol. $\left.138 \mathrm{v}^{\circ}\right)$. 
Cette "noble colère du lion" est empruntée à la Pharsale de Lucain $^{60}$ et se retrouve dans un distique du De mirabilibus mundi que l'on attribue à Thierry, abbé de Saint-Trond de 1099 à 1107 :

Parcere prostratis scit nobilis ira leonis

Tu quoque fac simile quisquis dominaris in orbe ${ }^{61}$,

distique que reproduit fidèlement l'auteur du $D e$ bestiis, et qui sera peint en la chapelle Saint-Nicolas du palais du Latran à Rome ${ }^{62}$. Ce sens est encore rappelé au tympan de la façade occidentale de la cathédrale de Jaca où un homme est accroupi entre les pattes du lion de gauche :

PARCERE STERNENTI LEO SCIT, CHRISTUSQUE PETENTI63 (fig. 5). "Le lion sait épargner à qui est prostré, le Christ à qui le supplie."

Mais c'est la troisième caractéristique du lion - le réveil des lionceaux au souffle du lion le troisième jour après leur naissance qui a eu la plus grande fortune en tant que figure de la Résurrection. A la suite du Physiologus tous les auteurs qui traitent des animaux en parlent : Isidore de Séville64, Raban Maur65, l'auteur du Physiologus ${ }^{66}$, l'auteur du De Bestiis ${ }^{67}$, Hildegarde ${ }^{68}$ ou encore Richard de Fournival69. On peut lire cette même interprétation du lion comme symbole de la rêsurrection chez Rufin d'Aquilée ${ }^{70}$, dans des écrits

60. Lucain, La guerre civile (la Pharsale), t. II (livres VI-X), éd. et trad. A. Bourgery et Max Ponchont, Paris, 1948, p. 25 (Coll. des univ. de France publ. sous le patronage de l'Assoc. Guillaume Budé).

61. Jean G. Préaux, * Thierry de Saint-Trond auteur du poème pseudo-ovidien De mirabilibus mundi ", dans Latomus, VI, 1947, p. 353-366 (en particulier p. 365).

62. Jean-Baptiste de Rossi, Inscriptiones christianae urbis Romae septimo saeculo antiquiores, II, pars prima, Rome, 1888, p. $426, \mathrm{n}^{\circ} 60$; voir aussi d'autres emplois du distique, Hans Walther, Carmina medii aevi posterioris latina. II, 3. Proverbia sententiaeque latinitatis medii aevi..., Göttingen, 1965, p. 707, n² 20668.

63. Georges Gaillard, Les débuts de la sculpture romane espagnole Léon-faca-Compostelle, Paris, 1938, p. 106-109; pour la bibliographie plus récente, voir Serafin Moralejo, * Le origini del programma iconografico dei portali nel Romanico spagnolo ", dans Wiligelmo e Lanfranco nell'Europa romanica, Modène, 1989, p. 35-51, notamment p. 44.

64. $P L, 82$, col. 434.

65. $P L, 111$, col. 218 (De universo).

66. $P L, 171$, col. 1217 (Physiologus).

67. $P L, 177$, col. 57.

68. PL, 197, col. 1314-1315 (Liber subtilitatum diversarum naturarum creaturarum, liber VII, De animalibus).

69. Li Bestiaires d'amours di maistre Richart de Fornival e li response du Bestiaire, éd. Cesare Segre, Milan et Naples, 1957, p. 54. On peut voir aussi le Bestiaire moralisé de Gubbio du milieu du XIII siècle et le Libellus de natura animalium du Xve siècle publiés par Annamaria Carrega et Paola Navone, dans Le proprietà degli animali, présenté par Giorgio Celli, Gênes, 1983, p. 39 et 261.

70. Tyrannii Rufini, Opera, p. 193-194; PL, 21, col. 301-302. 


\section{6}

COMPTES RENDUS DE L'ACADÉMIE DES INSCRIPTIONS

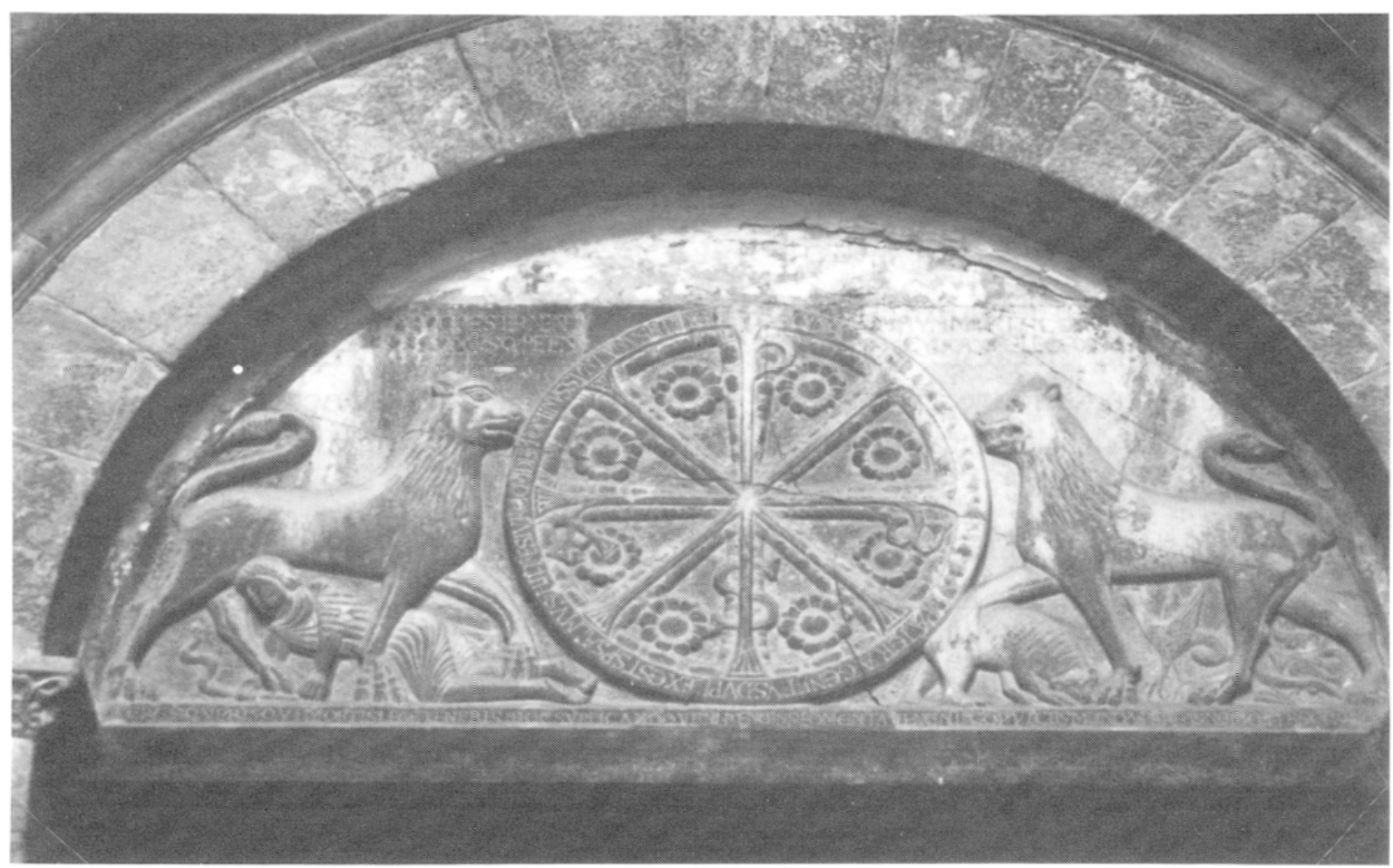

FIG. 5. - Jaca (Espagne), cathédrale, tympan de la façade occidentale (CESCM, photothèque).

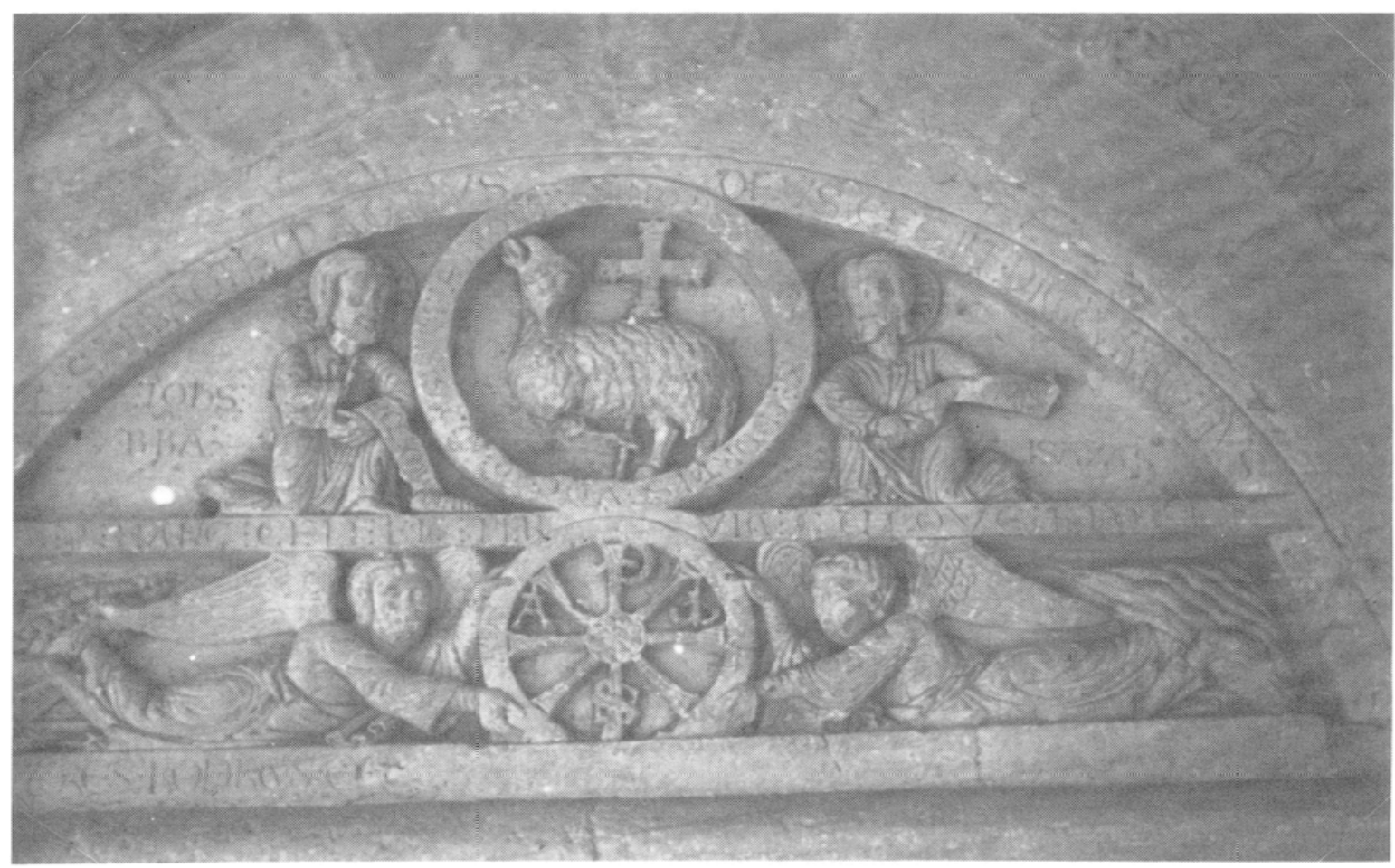

Fig. 6. - Armentia (Espagne), église $S$. Andrès, mur extérieur sud, tympan en réemploi (CESCM, photothèque) 
attribués à tort à saint Jérôme ${ }^{71}$ et à saint Augustinn', chez Paulin de Nole ${ }^{73}$, Anselme de Laon ${ }^{74}$, Geoffroy d'Admont ${ }^{75}$.

Cette figure du lion comme symbole de la résurrection a eu d'autant plus de succès que le lion est devenu l'attribut de l'évangéliste Marc et que le lion de Marc va à son tour, sous l'influence du Physiologus, symboliser le Christ ressuscité. Irénée de Lyon avait rapproché la vision des quatre animaux d'Ézéchiel $(\mathrm{I}, 5-10)$ des quatre Vivants de l'Apocalypse (IV, 6-7 $)^{76}$ et il en avait fait l'application aux quatre évangélistes. Jérôme adopta l'attribution proposée par Épiphane, l'homme à Matthieu, le lion à Marc, le bouf à Luc, l'aigle à Jean, en se fondant sur les débuts de chaque évangile : le lion est Marc parce que Jean-Baptiste paraît dans le désert, comme l'annonçait le prophète Isaïe : "Une voix crie dans le désert, préparez le chemin du Seigneur " (Marc, I, 3-4) et que le lion est l'animal du désert ${ }^{77}$. Grégoire le Grand a trouvé, dans les Moralia in $\mathfrak{F} o b$, une admirable formule pour montrer que les quatre figures des évangélistes représentent la totalité du mystère du Christ, "homo nascendo, vitulus moriendo, leo resurgendo, aquila ad caelos ascendendo „78. Dans ses homélies sur Ézéchiel il voit, dans le lion qui dort les yeux ouverts, une figure de la Résurrection : le Christ peut dormir dans la mort par son humanité, mais par sa divinité il veille pour toujours ${ }^{79}$. Il sera repris textuellement par Walafrid Strabon dans son Expositio in quatuor evangelia80, et par Druthmar de Corbie dans son Expositio in Mattheum evangelistam ${ }^{81}$. Le verbe surgere ici utilisé est celuilà même qui est employé dans la guérison du paralytique, de l'homme à la main paralysée, des dix lépreux, dans la résurrection de la fille de Jaïre et du jeune homme de Naïn, et bien sûr dans la Résurrection

71. $P L, 23$, col. 1313.

72. $P L, 35$, col. 2201. Serait d'Alcuin.

73. Epistulae, éd. Guillaume de Hartel, Vienne, 1894, p. 174 (Corpus scriptorum ecclesiasticorum latinorum, 29); PL, 61, col. 267.

74. $P L, 114$, col. 719 (Glossa ordinaria, attribuée à tort à Walafrid Strabon).

75. $P L, 174$, col. 1140-1141 (Liber de benedictionibus facob patriarchae ad caput XLIX Genesos).

76. Contre les hérésies..., livre III, éd. et trad. F. Sagnard, Paris et Lyon, 1952, p. 192-193 (Sources chrétiennes); F. van der Meer, Majestas Domini. Théophanies de l'Apocalypse dans l'art chrétien. Études sur les origines d'une iconographie spéciale du Christ, Rome et Paris, 1938, p. 223-228.

77. PL, 23, col. 248; Opera. Pars 1. Opera exegetica. 7. Commentariorum in Matheum libri IV, Turnhout, 1969, p. 3 (Corpus christianorum. Series latina LXXVII) et PL, 26, col. 19.

78. Moralia in fob libri XXIII-XXXV, éd. Marc Adriaen, Turnhout, 1985, p. 1615 (Corpus christianorum. Series latina, CXLIII B); PL, 76, col. 625.

79. Homiliae in Hiezechihelem prophetam, éd. Marc Adriaen, p. 47-48;PL, 76, col. 815.

80. $P L, 114$, col. 863 (l'attribution à Strabon est douteuse); $P L, 30$, col. 534 (Expositio quatuor evangeliorum placée dans les euvres de saint Jérôme mais des vile-vile siècles ou, pour certains, de W. Strabon).

81. PL, 106, col. 1265 : qui homo factus est nascendo, vitulus moriendo, leo factus est resurgendo, aquila exstitit ascendendo.

1991 
du Christ. L'identification du lion à la Résurrection dérive évidemment du Physiologus, comme le dit un commentaire sur l'Apocalypse attribué à tort à Alcuinn ${ }^{82}$.

Les textes qui accompagnent les enluminures des évangéliaires font souvent état de l'interprétation lion-résurrection pour le symbole de l'évangéliste Marc. C'est le cas pour les évangéliaires carolingiens ou ottoniens de Saint-Emmeran de Ratisbonne ${ }^{83}$, de la SainteChapelle de Paris ${ }^{84}$, de Gérard de Luxeuil ${ }^{85}$, d'Henri II ${ }^{86}$, de la cathédrale de Bamberg87, comme pour ceux de l'Ambrosiana de Milan, de 996-100288, de Stuttgart, de 1020-104089, de Cologne, vers $1000^{\circ 0}$, qui ont le même texte, ou encore, au XII ${ }^{e}$ siècle, pour les évangiles d'Henri le Lion ${ }^{91}$ ou la Bible d'Averboden'2.

L'homélie de Grégoire le Grand sur la vision d'Ézéchiel entra de bonne heure dans l'office comme lecture (épître) pour les fêtes des évangélistes. La symbolique lion-Résurrection pénétra dans toute la liturgie, prose de l'Épiphanie du début du $\mathrm{x}^{\mathrm{e}}$ siècle ${ }^{93}$, tropaires de l'office de Pâques d'Apt ${ }^{94}$ et de Winchester95, visitatio sepulchri du drame de Pâques ${ }^{96}$, hymnes d'Abélard et d'Adam de Saint-Victor pour les fêtes du samedi saint et de Pâques ${ }^{97}$. Le rapprochement

82. $P L, 100$, col. 118 .

83. Wilhem Koehler et Florence Muetherich, Die karolingische Miniaturen. V. Die Hofschule Karls des Kahlen, Berlin, 1982, p. 193 : "Hic leo surgendo portas confregit Arverni - Qui numquam dormivit nusquam dormitat in aevum " (Munich, Bayerische Staatsbibliothek, $\mathrm{Clm} 14000$, fol. $16 \mathrm{v}^{\circ}$, Codex aureus).

84. Die lateinischen Dichter des deutschen Mittelalters. V. Die Ottonzeit, par Karl Strecker, ct Norbcrt Fickermann, Gabriel Silagi et Bernhard Bischoff, Leipzig/Berlin/Munich, 1937-1979, p. 430 (M.G.H., Poetae latini medii aevi, V) : Est homo nascendo, vitulusque sacer moriendo - Et leo surgendo caelos aquilaque petendo (Paris, Bibl. nat., lat. 8851, fol. $1 \mathrm{v}^{\circ}$ ).

85. Ibid., p. 430-431 (Paris, Bibl. nat., nouv. acq. lat. 2196, fol. 19).

86. Ibid., p. 445.

87. Ibid., p. 435 : Ecce leo fortis transit discrimina mortis (Munich, Bayer. Staatsbibl., Clm. 4454, fol. $\left.86 \mathrm{v}^{\circ}\right)$.

88. Ibid., p. 450 : Nascendo quia factus homo, vitulus moriendo - Et leo surgendo sicutque aquila astra petendo (Milan, Codex Ambrosianus C 53).

89. Die Ottonische Kölner Malerschule, par Peter Bloch et Hermann Schnitzler, Bd. I, Katalog und Tafeln, Düsseldorf, 1967, p. 62 (Württembergische Landesbibliothek, Bibl. $4^{\circ}$ 2, fol. $\left.9 \mathrm{v}^{\circ}\right)$.

90. F. van der Meer, Majestas Domini..., p. 351.

91. Hanns Swarzenski, Monuments of Romanesque Art. The Art of Church Treasures in North-Western Europe, Londres, s.d., p. 78-79, fig. 478, pl. 206 : Qui catulus dormit patris ad vocem leo surgit.

92. C. R. Dodwell, Painting in Europe 800 to 1200, Harmondsworth, 1971, fig. 178 : Progenies fude Marci describitur ore - Imperium mortis qui destruxit leo fortis (Liège, Bibl. de l'Université, ms. 363, fol. 57).

93. Richard L. Crocker, The Early Medieval Sequence, Berkeley, Los Angeles, Londres, 1977, p. 76.

94. Apt, Bibl. mun., mss. 17 et 18 .

95. Oxford, Bodl. 775 ; Cambridge, Corpus Christi College, ms. 473.

96. Karl Young, The Drama of the Medieval Church, Oxford, s.d., p. 262 : Alleluia, resurrexit Dominus, hodie resurrexit leo fortis, Christus, Filius Dei.

97. Peter Abelard's hymnarius Paraclitensis. An annotated edition par Joseph Szöverffy, II. The Hymnarius Paraclitensis, Text and Notes, Albany (USA), 1975, p. 120, 122, 132 : 
se trouve aussi au $\mathrm{XII}^{\mathrm{e}}$ siècle, chez Hildegarde ${ }^{98}$, ou chez les poètes comme Baudri de Bourgueil ${ }^{99}$ et Pierre Riga ${ }^{100}$. Le troubadour Rigaut de Barbezieux rappellera, lui, cette caractéristique du lion mais en y voyant une figure de l'Amour qui viendra le guérir de ses souffrances ${ }^{101}$.

Les inscriptions confirment dans des œuvres nombreuses et variées, que l'intention de l'auteur du programme était bien de faire du lion une figure du Ressuscité. Sur un devant d'autel de la cathédrale de Sens de 989 on pouvait lire que " le lion fort signifie le Christ vainqueur de la mort ", VICTOREM MORTIS CHRISTUM SIGNAT LEO FORTIS ${ }^{102}$, et au début du $\mathrm{XI}^{\mathrm{e}}$ siècle l'animal symbolique de Marc est accompagné, sur l'ambon d'Henri II à la cathédrale d'Aixla-Chapelle du distique :

MARCE, LEO FORTIS, FORTEM RESONARE VIDERIS

CERTA RESURGENDI PER QUEM SPES VENERAT ORBI ${ }^{103 .}$

C'est par le lion fort qu'une espérance de résurrection est désormais assurée pour le monde. Sur un tympan roman fixé à l'extérieur du mur sud de l'église d'Armentia, près de Vitoria, l'Agneau crucifere est accompagné d'une inscription qui explique que l'agneau du Sacrifice est aussi le lion fort qui, par sa mort, a vaincu la mort :

AGNUS SUM, LEO FORTIS, MORS EGO SUM MORTIS VOCOR (fig. 6).

" Je suis l'agneau, je suis appelé le lion fort, moi je suis la mort de la mort ${ }^{104}$. Si, à Armentia, l'inscription renvoie au symbole du lion sans qu'il y ait une iconographie correspondante, au tympan de la porte occidentale de la cathédrale de Jaca le lion de droite

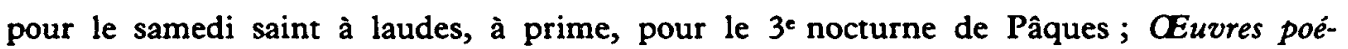
tiques d'Adam de Saint-Victor, éd. Léon Gautier, Paris, 3e éd., 1894, p. 39 et 48, pour Pâques.

98. Hildegardis Scivias, éd. Adelgundis Führkötter, o.s. B., et Angela Carlevaris, o.s. B., Pars III, Turnhout, 1978, p. 562 (Corpus christianorum, Continuatio Mediaevalis XIII A).

99. Les auvres poétiques de Baudri de Bourgueil (1046-1130), éd. Phyllis Abrahams, Paris, 1926, p. 5.

100. $P L, 171$, col. 1390 : leo vero quando resurgit... (dans les œuvres d'Hildebert de Lavardin).

101. Rigaut de Berbezil, Liriche, éd. Alberto Varvaro, Bari, 1960, p. 96-97.

102. Ch. Rohault de Fleury, La Messe. Études archéologiques sur ses monuments, Paris, I, 1883, p. 185.186; Max Quentin, * Communication sur le procès-verbal de ce qui s'est trouvé tant dans le sanctuaire que dessous et autour du grand autel de l'église métropolitaine de Saint-Estienne de Sens lors de la démolition dudit autel... pour construire le grand autel de marbre ", dans Bull. du Comité histor. et scientif. des arts et monuments; archéologie, beaux-arts (Comité des travaux histor. et scientif.), II, 1850, p. 93-96.

103. Die lateinischen Dichter des deutschen Mittelalters, V, p. 357.

104. Poitiers, Centre d'études supérieures de civilisation médiévale, photothèque. 


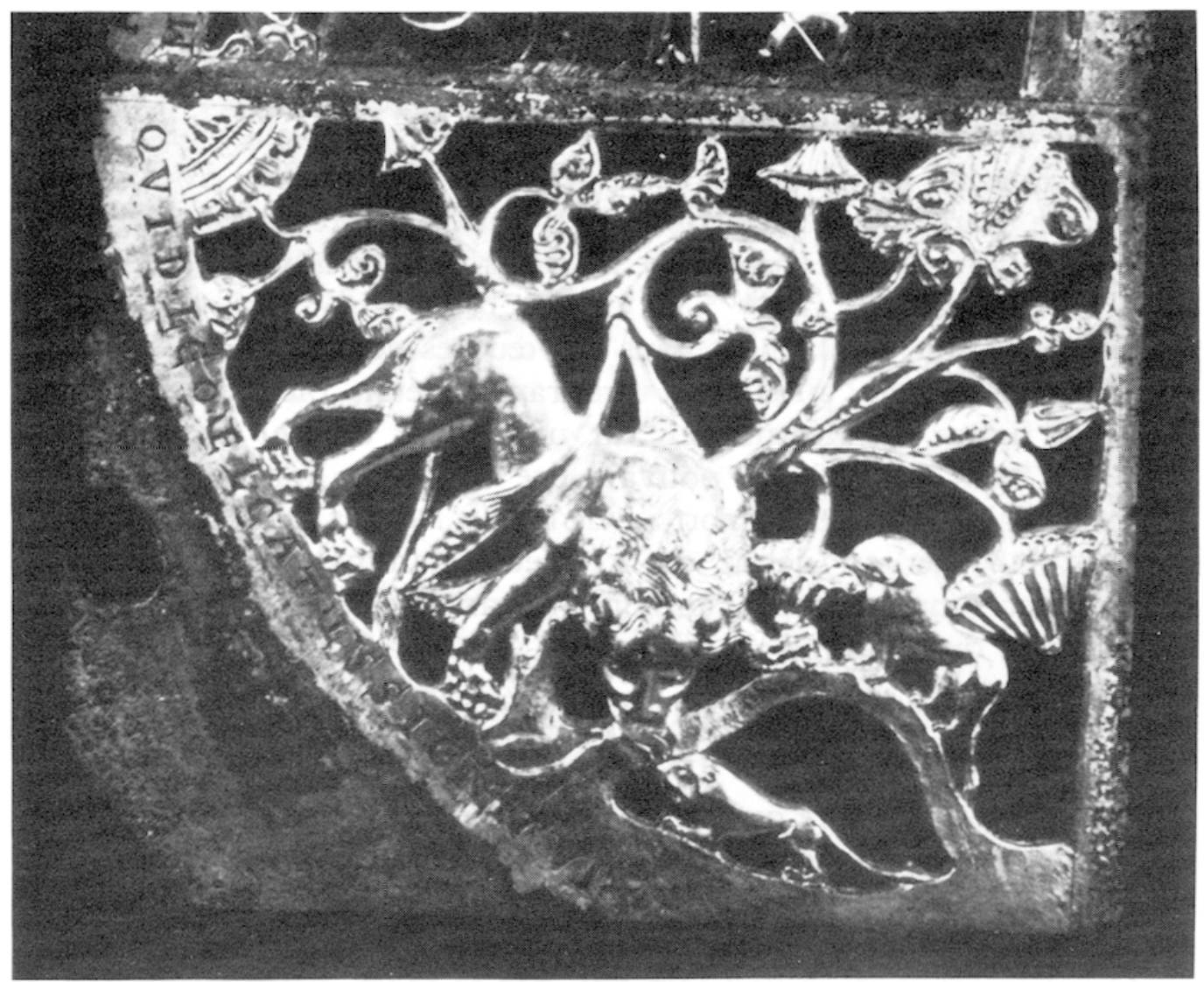

FIG. 7. - Kremsmünster (Autriche), flabellum : lion et lionceaux (H. Swarzenski, Monuments of Romanesque Art.

The Art of Church Treasures in North-Western Europe, Londres, 1953, p1. 144).

(pour le spectateur), qui foule aux pieds un ours et un basilic, est bien le lion fort de la résurrection qui a mis fin à l'empire de la mort :

IMPERIUM MORTIS CONCULCANS EST LEO FORTIS.

"Le lion fort terrasse l'empire de la mort "105,

ce qui est, à deux mots près, le vers de l'évangéliaire d'Averboden. Le Physiologus et son interprétation christologique sont mis en parallèle par l'iconographie elle-même sur un flabellum en cuivre doré de la seconde moitié du XIr siècle en l'abbaye de Kremsmünster (Autriche), où l'on voit figurés d'une part un lion et ses petits apparemment mort-nés, de l'autre les saintes femmes au tombeau. Une inscription commente chaque scène, pour la première :

QUID LEO VEL CATALUS SIGNENT VIX EXPRIMET ULLUS, " ce que le lion et son petit signifient on peut à peine l'exprimer " (fig. 7),

105. Georges Gaillard, Les débuts de la sculpture romane espagnole Léon-Faca-Compostelle, Paris, 1938, p. 108 ; Antonio Duran Gudiol, «Las inscripciones medievales de la provincia de Huesca ", dans Estudios de edad media de la corona de Aragon, vol. VIII, 1967, p. $56, n^{\circ} 69$. 
et pour la seconde :

MYSTICUS ECCE LEO SURGIT BARATRO POPULATO, " voici que le lion mystique se lève de l'abîme qu'il a détruit "106.

A la fin du XII $^{\mathrm{e}}$ siècle on retrouve le Physiologus, et le rapprochement qui est fait avec la bénédiction de Jacob (Genèse, XLIX, 9) mise en rapport avec la Résurrection dans le "retable " de Klosterneubourg : la légende épigraphique qui accompagne la bénédiction de Jacob dit que « en nous rachetant l'agneau devient le grand lion de Juda " et Jacob touche de sa baguette deux lions endormis en disant : "Qui le fera lever ?"107 (fig. 8).

Deux autres exemples explicites sont fournis par des croix du XIII' siècle. Sur un crucifix de l'abbé Henri Ier (1197-1223) à Engelberg figuraient, aux quatre bras de la croix, les médaillons des quatre évangélistes, et avec Marc et le lion on pouvait lire :

†IN TRIDUO SURGENS LEO FIT DEUS ISTEQUE MARCUSt, * le lion représente Dieu qui ressuscite le troisième jour et aussi Marc "108,

et la croix de l'abbaye de Clairmarais à Saint-Omer porte de même l'évangéliste Marc avec le commentaire épigraphique suivant :

TEFFIGIAT MARCUM LEO CUJUS LITTERA CLAMAT

QUANTA SURREXIT VI TUA, CHRISTE, CARO109,

qui est une citation du Floridus aspectus de Pierre Riga110. Le rapprochement devient si évident qu'on ne le commentera plus. Dans un vitrail qui illustre la Résurrection à la cathédrale de Bourges, le lion qui donne vie à d'autres lions a une brève inscription : HOC

106. H. Swarzenski, Monuments of Romanesque Art. The Art of Church Treasures in NorthWestern Europe, Londres, s.d., p. 64, fig. 321, pl. 144 ; L'art roman. Catalogue, Barcelone et Compostelle, 1961, p. 441-442, $\mathrm{n}^{\circ} 1162$, pl. 73 ; Ausstellung romanische Kunst in Oesterreich, Krems an der Donau, 1964, p. 181-182, n' 129, pl. 29 ; Ornamenta ecclesiae. Kunst und Künstler der Romanik. 1. Katalog zur Ausstellung des Schnütgen-Museums in der fosefHaubrich-Kunsthalle, Cologne, 1985, p. 470-471, C 48.

107. H. Buschhausen, Der Verduner Altar..., p. 68 et pl. 37 : Nos REDIMENS AGNUS EX JUDA FIT MAGNUS, et : QUIS SUSCITABIT EUM ?

108. Franz Xaver Kraus, Die christlichen Inschriften der Rheinlande von der mitte des achten bis zur mitte des dreizehnten fahrhunderts, Fribourg-en-Br. et Leipzig, 1894, p. 28, $\mathrm{n}^{\circ} 58$.

109. L. Deschamps de Pas, « Orfêvrerie du XIII siècle. La croix de Claimarais *, dans Annales archéologiques, XIX, 1854, p. 285-293, h.-t. ; Épigraphie du département du Pas-deCalais, publié par la Commission départ. des monum. histor., V, Arras, 1892, p. 124-126; Les trésors des églises de France, Paris, 2єéd., 1965, p. 25-26, n ${ }^{\circ} 55$, pl. 120.

110. PL, 171, col. 1390 (Cf. Mgr. P. Glorieux, Pour revaloriser Migne. Tables rectificatives, Lille, 1952, p. 66). 


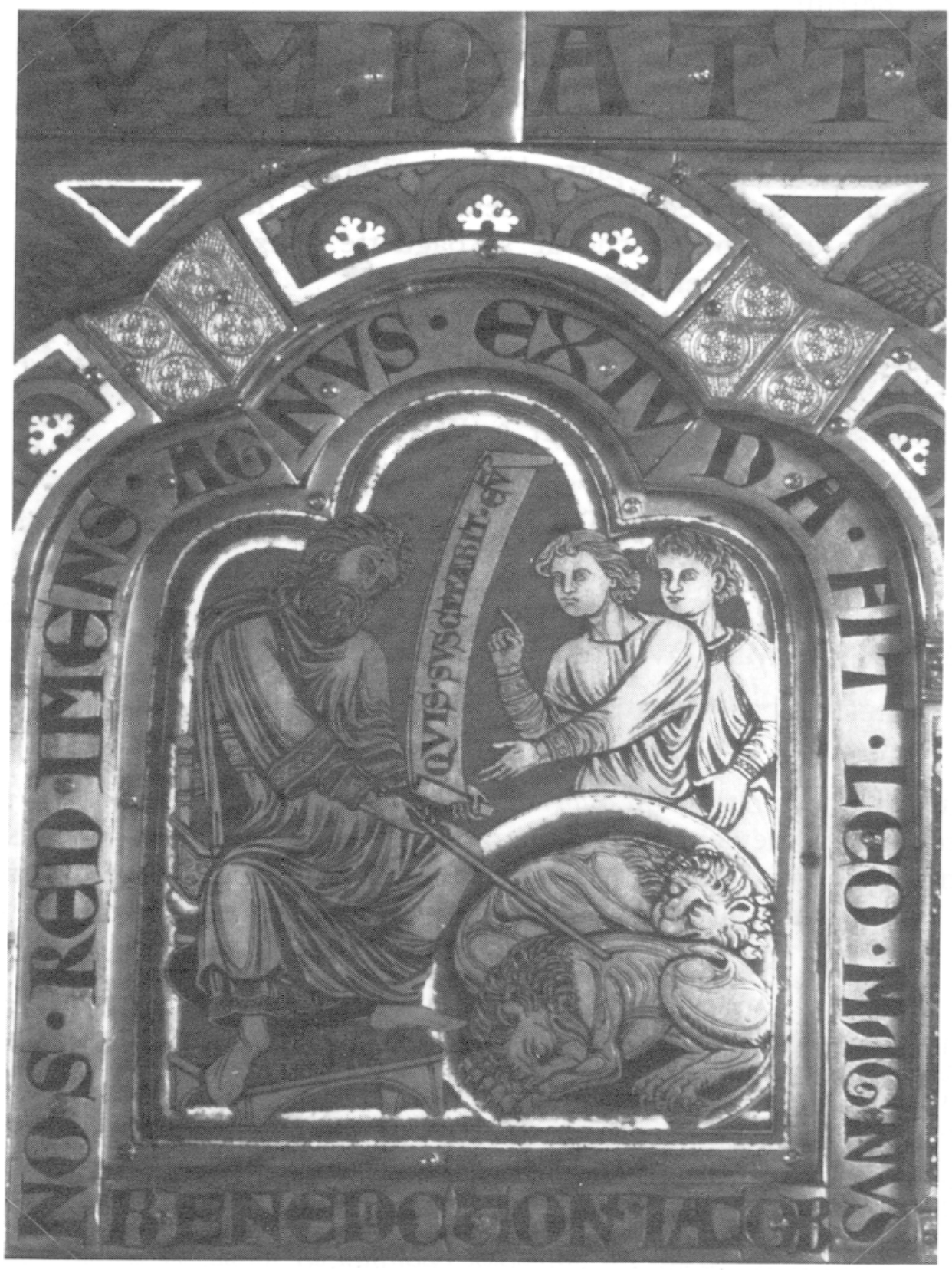

Fig. 8. - Klosterneubourg (Autriche), retable : bénédiction de Jacob (H. Buschhausen, Der Verduner Altar..., Vienne, 1980, pl. 37). 
LEO FORMAS'11, tandis que sur le vitrail du chœur de la cathédrale de Lyon, de 1215-1220, le lion qui souffle sur ses petits n'est plus accompagné que du mot : LEO ${ }^{112}$. Cette iconographie sera aussi celle que le Guide de la peinture du xve siècle recommandera aux artistes byzantins pour l'ensevelissement du Christ ${ }^{113}$.

Restent les inscriptions qui illustrent l'Apocalypse. Nul n'était capable d'ouvrir le livre scellé de sept sceaux. L'un des vingt-quatre vieillards qui entouraient le trône dit alors : "Il a remporté la victoire, le lion de la tribu de Juda, le rejeton de David; il ouvrira donc le livre aux sept sceaux. "Alors apparut un agneau, comme égorgé, portant sept cornes et sept yeux qui sont les sept esprits de Dieu. Il prit le livre et il brisa les sept sceaux. Ainsi s'exprime l'auteur de l'Apocalypse, au chapitre v. L'Agneau, c'est le Christ de la Passion mort sur la croix, le Lion c'est le Christ vainqueur de la mort et ressuscité. C'est aussi la nature humaine et la nature divine de l'Homme-Dieu, comme l'indique l'inscription composée par l'abbé Suger pour un des vitraux de Saint-Denis :

QUI DEUS EST MAGNUS, LIBRUM LEO SOLVIT ET AGNUS

AGNUS SIVE LEO FIT CARO JUNCTA DEO 114

Une série d'inscriptions renvoie expressément à Apocalypse, $V$, 5: sur un lion qui galope, peint à l'époque romane dans l'église de Saint-Romain-le-Puy, est inscrit : VICIT LEO ${ }^{115}$, et un VICIT LEO DE TRIBU JUDA accompagne le corps du Christ dans une peinture murale du XIve siècle en l'église Notre-Dame-du-Bourg de Rabastens ${ }^{116}$.

Cette référence à l'Apocalypse et au Christ victorieux de la fin des temps a souvent une forme liturgique ${ }^{117}$. Ainsi sur la mandorle

111. Vitrail à gauche de la chapelle axiale du déambulatoire. Ni l'iconographie, ni l'inscription ne sont citées dans Les vitraux du Centre et des pays de la Loire, Paris, 1981, p. 170 (Corpus vitrearum. France. Série complémentaire. Recensement des vitraux anciens de la France, vol. II).

112. CIFM, 17, Ain, Isère, Rhône, Savoie, Haute-Savoie, par R. Favreau, J. Michaud, B. Mora, Rhône, $n^{\circ} 8$ (à paraître en 1992).

113. Manuel d'iconographie chrétienne grecque et latine..., par P. Durand, Paris, 1845, p. 144-145.

114. OEuvres complètes de Suger, éd. A. Lecoy de La Marche, Paris, 1867, p. 204 ; Louis Grodecki, Les vitraux de Saint-Denis. Étude sur le vitrail au XII' siècle, Paris, 1976, p. 101 (médaillon perdu).

115. Paul Deschamps et Marc Thibout, "A propos de nos plus anciennes peintures ", dans le Bulletin monumental, CXI, 1953, p. 395, ill.

116. Guy Ahlsell de Touza, * Les peintures murales dans les chapelles du chœur de l'église Notre-Dame-du-Bourg de Rabastens-sur-le-Tarn ", dans Actes du 96 Congrès national des Sociétés Savantes, Toulouse, 1971. Archéologie occitane, Moyen Âge et époque moderne, II, p. 252-257.

117. On la trouve dans une prose de l'Épiphanie remontant au moins au début du $\mathrm{x}^{\mathrm{e}}$ siècle (Richard L. Crocker, The Early Medieval Sequence, Berkeley, Los Angeles, Londres, 1977, p. 76). 


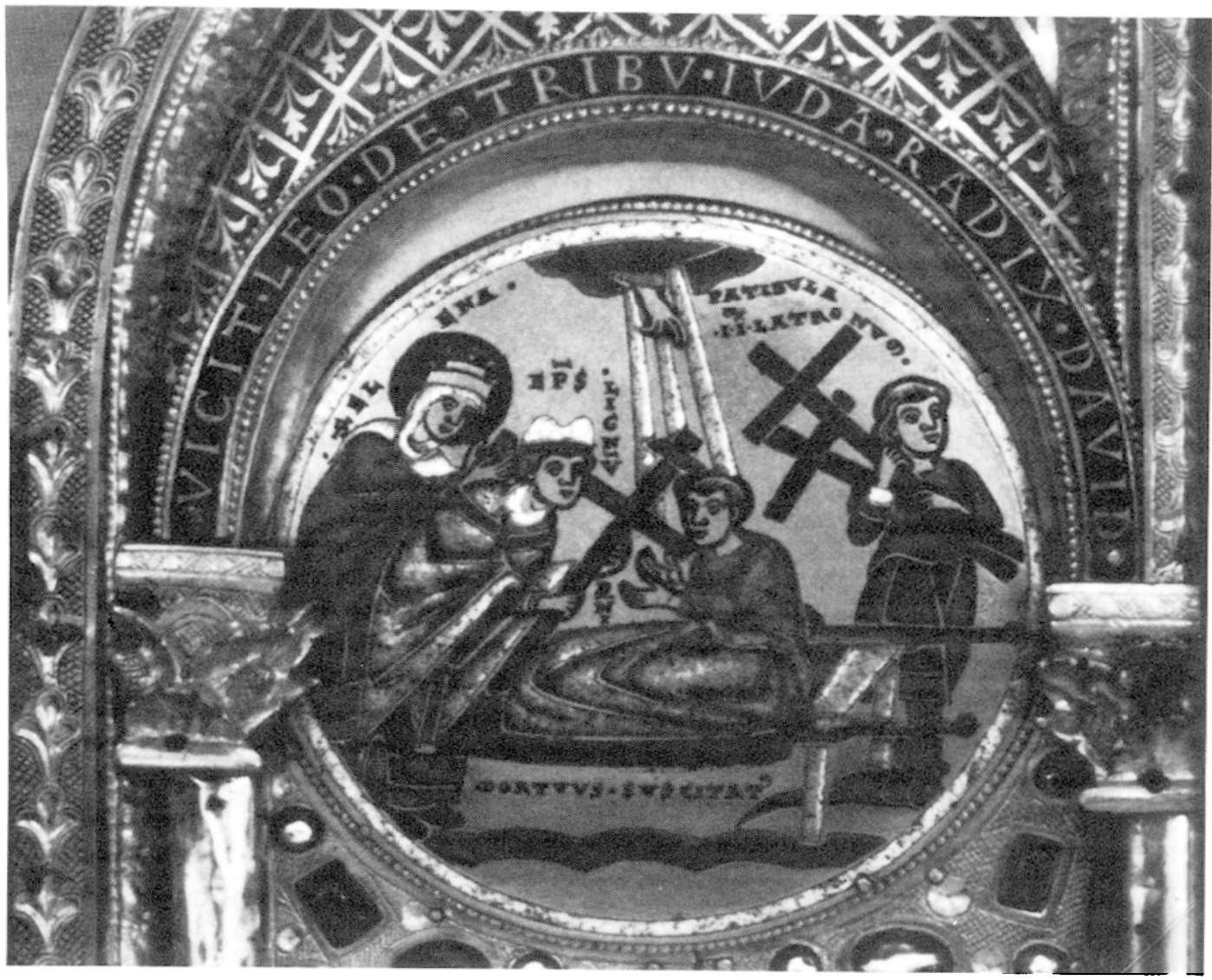

FIG. 9. - New York (USA), Pierpont Morgan Library, triptyque de Stavelot : découverte de la Vraie Croix par sainte Hélène (The Stavelot Triptych. Mosan Art and the Legend of the True Cross, Oxford, New York, Londres, 1980, pl. 1).

du Christ au tympan de Moradillo de Sedano, de 1188 , le vicit LeO DE TRIBU JUDA RADIX DAVID (Apoc., V, 5) est complété par un ALlELUIA du temps pascal118. Mais surtout ce verset est à diverses reprises associé au répons «Ecce crucem Domini fugite partes adversae " dans les offices de l'Invention et de l'Exaltation de la Sainte Croix et du dimanche de Pâques ${ }^{119}$, sur la croix pectorale du XII ${ }^{e}$ siècle au trésor de la cathédrale d'Aix-la-Chapelle ${ }^{120}$, le triptyque de Stavelot, du milieu du XII siècle, conservé à New York121 (fig. 9),

118. Éliane Vergnolle, «Le tympan de Moradillo de Sedano : autour du maître de l'Annonciation-Couronnement de Silos ", Actas del XXIII Congresso Internacional de Historia del arte, Granada, 1973, I, Grenade, 1976, p. 545-553.

119. Corpus antiphonalium officii, éd. René-Jean Hesbert, Romc, III, $n^{\circ} 2500$, p. 185 , et IV, $n^{\circ} 6581$, p. 150.

120. F. X. Kraus, Die christlichen Inschriften der Rheinlande, II, p. 224, n० 482 .

121. A la Pierpont Morgan Library, A. Frolow, La relique de la Vraie Croix..., Paris, 1961 , p. 335-336, n 347 (Archives de l'Orient chrétien, 7) ; Marie-Madeleine Gauthier, Emaux du Moyen Age occidental, Paris, 1972, p. 343, $\mathrm{n}^{\circ} 81$; The Stavelot Triptych. Mosan Art and the Legend of the True Cross, Oxford/New York/Londres, 1980, p. 24 et pl. 1. 
la croix de Castelnau-de-Montmirail du début du xive siècle $^{122}$, une cloche de Corneilla-de-Conflent du XIV e siècle ${ }^{123}$. Répons et verset sont aussi une des prières pour écarter orages et tempêtes ${ }^{124}$.

Le rappel de l'Apocalypse peut encore se faire par le simple rapprochement du lion et de l'agneau.

\section{HIC DOMINUS MAGNUS LEO CRISTUS CERNITUR AGNUS}

est-il inscrit au tympan du porche de la cathédrale de Vérone ${ }^{125}$, ou, au tympan de l'église d'Armentia déjà cité :

AGNUS SUM LEO FORTIS, MORS EGO SUM MORTIS VOCOR.

"Il est appelé l'agneau pour son innocence, il est appelé lion pour sa puissance ", écrit Grégoire le Grand"26. "C'est le même Christ qui est agneau par sa mort d'innocent, qui devient lion par sa forte victoire sur la mort ", commentera Rupert de Deutz ${ }^{127}$. Il se peut que ce soit aussi une interprétation des deux figures allégoriques, ARIES, LEO, du Musée des Augustins de Toulouse ${ }^{128}$. Lorsque dans certaines épitaphes le défunt est dit "lion pour les méchants, agneau pour les doux ", tumidis leo, mitibus agnus, c'est, sous couvert d'un renvoi à l'Apocalypse, une façon de dire qu'il a fidèlement suivi l'exemple du maître'129.

Quand on reprend l'ensemble des inscriptions qui accompagnent la représentation du lion au Moyen Âge, on constate que la référence à l'Ancien Testament se traduit ordinairement par une image négative du lion, à travers les figures de Samson et de Daniel en particulier. Le lion est alors figure du mal, du diable, de la mort. Assez souvent, il apparaît dans le contexte du Christ ressuscité vainqueur des forces mauvaises. Avec le Physiologus et les bestiaires, les aspects positifs du lion l'emportent, sa vigilance, sa mansuétude, et sa puissance de vie lorsqu'il redonne vie aux lionceaux. Ce dernier caractère, figure de la Résurrection du Christ, l'emporte de beaucoup dans l'iconographie, d'autant plus qu'on l'appuie sur un obscur verset de

122. A. Frolow, La relique de la Vraie Croix..., p. 490, $n^{\circ} 672$.

123. Baron de Rivières, "Études campanaires *, dans Bulletin monumental, LVII, 1891-1892, p. 28.

124. Adolph Franz, Die kirchlichen Benediktionen im Mittelalter, II, Graz, 1960, p. 80, 82, 87, 91, 92, 94, 97, 98, 104.

125. Arthur Kingsley Porter, Lombard Architecture, III, Oxford, 1917, p. 475.

126. Moralia in fob. Libri XXIII-XXXV, éd. Marc Adriaen, p. $1535 ; P L, 76$, col. 560.

127. Apocalypsim foannis apostoli commentariorum liber IV, $P L, 169$, col. 928.

128. O. Beigbeder, "Symbolisme du lion ", dans Zodiaque, 50, octobre 1961, p. 11.

129. Épitaphes de Boson, abbé du Bec, en 1136, de Geoffroi de Garosse à Carpentras en 1211 ou 1220, d'Évrard de Fouilloy, évêque d'Amiens, en 1223, inscription du pape Innocent IV à Lyon en 1246. 
la Genèse et sur un bref passage de l'Apocalypse, desquels il permet une nouvelle et forte interprétation.

Représenté dès les temps les plus anciens le lion peut encore avoir, à l'époque romane, une fonction purement décorative. Mais, en particulier à partir du XII $^{e}$ siècle, il a souvent, par la vertu des bestiaires, un sens christologique. Rupert de Deutz reconnaît que les anciens voyaient dans le lion la figure du diable, mais il préfere, quant à lui, y voir la figure du Christ, le "Dieu très fort ", comme le lui suggère le patriarche Jacob ${ }^{130}$. Dans la représentation de Samson et du lion, à San Silvestro de Nonantola, le lion devient même une figure du Christ, puisque l'inscription rappelle l'énigme proposée aux Philistins par Samson (Juges, XIV, 18):

ET DE FORTE DULCEDO, DE COMEDENTE CIBUS ${ }^{131}$.

La réponse était l'essaim d'abeilles et le miel que Samson, à son retour de Timna, avait trouvé dans la gueule du lion mort, images qui peuvent directement s'appliquer au Christ, Dieu fait homme, mort sur la croix et donnant sa chair en nourriture. Paulin de Nole le disait déjà à propos de ce même passage : corpus feritatis erat ante, nunc Christi est ${ }^{132}$. Il est aussi significatif qu'Honorius dit d'Autun, dans son Speculum ecclesiae, reprenne, au jour de Pâques, tous les sens christologiques donnés à la figure du lion, et au premier rang d'entre eux celui de la Résurrection ${ }^{133}$. Les inscriptions qui accompagnent à cette époque la représentation du lion nous invitent à privilégier cette lecture, même lorsque l'iconographie est anépigraphe et ne fournit pas une évidente clé d'interprétation.

MM. Michel Mollat du Jourdin, Jean Delumeau, Bernard FRANK et Jacques MONFRIN interviennent après cette communication.

130. $P L, 168$, col. 566 .

131. Arthur Kingsley Porter, Lombard Architecture, III, 1917, p. 104.

132. Epistulae, éd. G. de Hartel, p. 173 (ep. XXIII) ; PL, 61, col. 267.

133. $P L, 172$, col. $935-936$. 